\title{
Patient variables and referral paradigms associated with osteoporosis screening and treatment in neurosurgical patients undergoing kyphoplasty
}

\author{
Simon Morr, MD, MPH, Hakeem J. Shakir, MD, Lindsay J. Lipinski, MD, \\ Vassilios G. Dimopoulos, MD, Jody Leonardo, MD, and John Pollina, MD \\ Department of Neurosurgery, Jacobs School of Medicine and Biomedical Sciences, University at Buffalo, State University of New \\ York; and Department of Neurosurgery, Kaleida Health, Buffalo, New York
}

\begin{abstract}
OBJECT Vertebral fractures are the most common osteoporotic fracture. Bone density testing and medical treatment with bisphosphonates or parathormone are recommended for all patients with an osteoporotic fracture diagnosis. Inadequate testing and treatment of patients presenting with low-impact fractures have been reported in various specialties. Similar data are not available from academic neurosurgery groups. The authors assessed compliance with treatment and testing of osteoporosis in patients with vertebral compression fractures evaluated by the authors' academic neurosurgery service, and patient variable and health-systems factors associated with improved compliance.
\end{abstract}

METHODS Data for patients who underwent percutaneous kyphoplasty for compression fractures was retrospectively collected. Diagnostic and medical interventions were tabulated. Pre-, intra-, and posthospital factors that had been theorized to affect the compliance of patients with osteoporosis-related therapies were tabulated and statistically analyzed.

RESULTS Less than $50 \%$ of patients with kyphoplasty received such therapies. Age was not found to correlate with other variables. Referral from a specialist rather than a primary care physician was associated with a higher rate of bone density screening, as well as vitamin D and calcium therapy, but not bisphosphonate/parathormone therapy. Patients who underwent preoperative evaluation by their primary care physician were significantly more likely to receive bisphosphonates compared with those only evaluated by a hospitalist. Patients with unprovoked fractures were more likely to undergo multiple surgeries compared with those with minor trauma.

CONCLUSIONS These results suggest poor compliance with current standard of care for medical therapies in patients with osteoporotic compression fractures undergoing kyphoplasty under the care of an academic neurosurgery service.

http://thejns.org/doi/abs/10.3171/2015.9.FOCUS15375

KEY WORDS kyphoplasty; osteoporosis; vertebral compression fracture

$\mathrm{O}$ STEOPOROSIS-RELATED compression fractures are estimated to affect more than 40 million people in the US yearly. The annual cost is reported to be more than $\$ 13$ billion, exceeding combined expenditures for breast and gynecological disease..$^{17,36}$ In Switzerland, expenditures for osteoporotic fractures surpass those for even stroke and myocardial infarction. ${ }^{26}$ Functional impairment and health complications associated with these fractures include back pain, decreased ambulation, pulmonary decline, and loss of independence..$^{18,21,33,40}$ Cement augmentation procedures, including vertebroplasty and balloon kyphoplasty, have been shown to effectively treat pain and significantly improve measured functional status. $15,16,25,28,35,42$

Vertebral fractures are the most common osteoporotic fracture and occur in $12 \%-25 \%$ of all persons aged 60 years or older. ${ }^{10,12}$ Approximately 700,000 of the 1.5 million annual fractures attributed to osteoporosis are vertebral fractures, almost 3 times more than the number of fractures of the hip and distal radius. ${ }^{37}$ Low bone mineral density, as measured with dual energy x-ray absorptiometry (DEXA) scanning, is associated with an increased risk of compres- 
sion fracture. ${ }^{3,20,22}$ Prolonged steroid use, female sex, older age, and smoking also increase fracture risk..$^{11,19,27,34}$ Treatment with bisphosphonates improves bone density and decreases fracture risk in patients with and without previous vertebral fractures. ${ }^{2,8}$ Lower bone mineral density and previous vertebral fractures are independent major risk factors for future osteoporotic fractures. ${ }^{5,9,38}$ Patients with previous vertebral fractures treated with vertebral cement augmentation are at an increased risk of repeat fracture at another level, especially the adjacent level. ${ }^{23,33,41}$ This association was suggested in a cohort study to be stronger in the thoracic spine than in the lumbar spine. ${ }^{40}$

Early treatment of osteoporosis in the elderly is essential to prevent complications such as hip fractures, which have a 1 -year postevent mortality rate of up to $20 \% .^{1,7}$ Randomized controlled trials have confirmed that medical treatment of osteoporosis significantly increases bone density, reduces fracture incidence, and slows progression of spinal deformity and height loss in women with vertebral fractures and/or postmenopausal women. $2,13,24$ The National Osteoporosis Foundation recommends bone density testing for all patients with a diagnosis of osteoporotic fracture, especially those fractures associated with minimal or no trauma. ${ }^{30}$ Initiation of medical treatment is recommended for all patients who have been diagnosed with hip or vertebral body fractures, regardless of bone density scan findings. ${ }^{14,30}$ Overwhelmingly inadequate diagnostic evaluation and treatment of patients presenting with low-impact fractures has been reported for hip, humerus, and spine fractures, ${ }^{31,39}$ as well as distal radius fractures. ${ }^{14}$ Osteoporosis is rarely addressed or listed as a secondary diagnosis at the time of discharge in patients with low-impact fractures, even in the classically highrisk population of postmenopausal, elderly white women. ${ }^{29,36}$ Literature from both orthopedic surgery and internal medicine groups has demonstrated severe deficits in point-of-care secondary prevention interventions among patients presenting with low-impact, likely osteoporotic fractures. ${ }^{6,14,31,39}$ Similar data are not available from academic neurosurgery groups.

Our aim in this study was to evaluate and address medical treatment of osteoporosis in patients undergoing vertebral augmentation at our academic neurosurgery department. A diagnosis of osteoporosis can be acquired by either a disease-defining fracture (including a vertebral compression fracture, in the setting of low or no impact) or a DEXA scan demonstrating a t-score of -2.5 or less (i.e., a bone density that is 2.5 standard deviations below that of the average 30-year-old woman). In the case of our patients who had all been diagnosed and surgically treated for osteoporotic vertebral fractures, the goal according to the guidelines would be that all such patients receive medical treatment, such as bisphosphonates. First, we hypothesized that point-of-care osteoporosis-directed diagnostic and therapeutic measures were adequately implemented in less than 50\% of patients who undergo kyphoplasty procedures performed by our neurosurgery service. Second, we hypothesized that no significant difference in diagnostic and therapeutic compliance with current medical management guidelines would be found between patients referred for neurosurgical intervention by a medical specialist, such as a primary care provider, and those encountered directly with a diagnosis of compression fracture by the neurosurgery service, such as through the emergency room.

\section{Methods}

Using the outpatient electronic medical record system (Medent) for the neurosurgery department, we identified all patients who underwent percutaneous kyphoplasty for compression fractures by our neurosurgery group between January 1, 2010, and January 1, 2012, using the following current procedural terminology codes (American Medical Association): 22523, 22524, 22525, 72291, and 72292. We performed detailed electronic chart reviews and tabulated several independent and dependent variables (Table 1). Diagnostic and therapeutic interventions were counted as performed regardless of whether they were performed before or after the encounter with our department and diagnosis of fracture. We used a 2-tailed Fisher's exact $2 \times 2$ contingency table to statistically analyze all variables except age. The correlation between patient age and other variables was analyzed using univariate logistic regression. This study was conducted in accordance with a HIPAA-compliant, institutional review board-approved protocol.

\section{Results}

A total of 108 patients underwent vertebral cement augmentation for compression fractures during the study period. Three of these patients were excluded from our analysis as the pathology findings were consistent with malignant disease (breast cancer, lung cancer, and lymphoma, respectively). Another patient treated for a compression fracture after a high-speed motor vehicle collision was excluded because this fracture was not considered osteoporotic.

Predictors of compliance and surgery characteristics are described in Table 2. The percentage of patients who received osteoporosis-related treatments was $<50 \%$ for all interventions (Table 3). DEXA screening was performed in only $10 \%$ of the patients who had undergone kyphoplasty. Only $13 \%$ of patients were treated with bisphosphonates. An overwhelming majority (94\%) of these patients were white, and our population was insufficiently diverse to analyze race for statistical significance. Medicare was the primary insurance provider for most patients (Table 4). The average age of the patients was $77.1 \pm 12.8$ years. Age was not found to correlate with other variables (Table 5).

Patients first encountered by the department in the outpatient setting were more likely to have at least 1 lumbar fracture compared with those who were examined for the first time in the hospital (Table 2). Patients with a medical history of unprovoked fractures were more likely to have undergone multiple surgeries compared with patients who had a known history of minor trauma. Nevertheless, no significant association could be established between injury mechanism, initial encounter in the emergency room versus outpatient setting, steroid use, smoking history, and sex on the one hand, and most parameters of osteoporosis evaluation and therapy on the other hand.

Patients referred by a specialist other than the primary 
TABLE 1. Description of independent and dependent variables

\begin{tabular}{|c|c|}
\hline Variable & Description \\
\hline \multicolumn{2}{|l|}{ Independent } \\
\hline Age & The patient's age at the time of the kyphoplasty is reported. \\
\hline Race & $\begin{array}{l}\text { Race according to the US Federal Census Bureau \& the Office of Management \& Budget is reported: White Non-Hispanic; } \\
\text { Black Non-Hispanic; Asian; Native American; Hispanic-White; \& Hispanic-Black. }\end{array}$ \\
\hline Sex & Patients categorized as male \& female. \\
\hline Initial encounter & $\begin{array}{l}\text { This variable distinguishes btwn patients who are referred to the neurosurgery service as an outpatient initially \& those who } \\
\text { are encountered via an inpatient consultation. Inpatient consultations include emergency room consultations \& consulta- } \\
\text { tions while the patients are on another service. }\end{array}$ \\
\hline Smoking history & Any previous history of smoking is reported as positive. \\
\hline Steroids & $\begin{array}{l}\text { Any history of prolonged steroid use recorded in the medication list in the chart prior to the kyphoplasty procedure is re- } \\
\text { corded. Short-term steroid therapy associated w/ fracture-related pain, such as a methylprednisolone sodium succinate } \\
\text { 7-day taper, is excluded. }\end{array}$ \\
\hline Mechanism & $\begin{array}{l}\text { Mechanisms included are unprovoked \& minor trauma. Unprovoked = patients who report no history of trauma associated } \\
\text { w/ the fracture presentation. Minor trauma = patients who have recorded mechanisms of injury that would not be associ- } \\
\text { ated w/ fractures in nonosteoporotic patients, e.g., ground-level fall. }\end{array}$ \\
\hline Referral source & $\begin{array}{l}\text { The distinction here is btwn patients referred to the neurosurgeon by their primary care physician \& those referred by } \\
\text { specialists other than their primary care physicians. }\end{array}$ \\
\hline Preop evaluation & $\begin{array}{l}\text { The distinction here is made btwn patients who have had preop clearance by their primary care physician \& those who have } \\
\text { had preop clearance by an in-house hospitalist. This independent variable is distinct from initial encounter as patients } \\
\text { who have been encountered in the hospital are at times discharged to be evaluated as an outpatient by their primary } \\
\text { care physician \& subsequently undergo surgical intervention on a scheduled outpatient basis. Patients who had both } \\
\text { inpatient hospitalist \& outpatient primary care clearance were included in the outpatient group. }\end{array}$ \\
\hline \multicolumn{2}{|l|}{ Dependent } \\
\hline DEXA & $\begin{array}{l}\text { This distinguishes btwn patients who have a bone density scan documented in the chart performed at any time during the } \\
\text { patient's care \& those who do not. }\end{array}$ \\
\hline Vitamin D & $\begin{array}{l}\text { This distinguishes btwn patients who have vitamin } D \text { treatment documented in the chart as being started at any time in the } \\
\text { course of the patient's care \& those who do not. }\end{array}$ \\
\hline Calcium & $\begin{array}{l}\text { This distinguishes btwn patients who have calcium treatment documented in the chart as being started at any time in the } \\
\text { course of the patient's care \& those who do not. }\end{array}$ \\
\hline Calcitonin & $\begin{array}{l}\text { This distinguishes btwn patients who have calcitonin treatment documented in the chart as being started at any time in the } \\
\text { course of the patient's care \& those who do not. }\end{array}$ \\
\hline Bisphosphonate & $\begin{array}{l}\text { This distinguishes btwn patients who have bisphosphonate treatment documented in the chart as being started at any time } \\
\text { in the course of the patient's care \& those who do not. }\end{array}$ \\
\hline $\begin{array}{l}\text { Recombinant parathor- } \\
\text { mone }\end{array}$ & $\begin{array}{l}\text { This distinguishes btwn patients who have parathormone treatment documented in the chart as being started at any time in } \\
\text { the course of the patient's care \& those who do not. }\end{array}$ \\
\hline $\begin{array}{l}\text { Vitamin D/calcium/ } \\
\text { calcitonin }\end{array}$ & $\begin{array}{l}\text { This distinguishes btwn patients who have vitamin } \mathrm{D} \text { or calcium or calcitonin treatment documented in the chart as being } \\
\text { started at any time in the course of the patient's care \& those who have none of those therapies documented. }\end{array}$ \\
\hline $\begin{array}{l}\text { Bisphosphonate/para- } \\
\text { thormone }\end{array}$ & $\begin{array}{l}\text { This distinguishes btwn patients who have bisphosphonate or parathormone treatment documented in the chart as being } \\
\text { started at any time in the course of the patient's care \& those who have neither documented. }\end{array}$ \\
\hline Thoracic & $\begin{array}{l}\text { This distinguishes btwn patients who have had at least } 1 \text { thoracic level treated w/ a kyphoplasty \& those who have not had } \\
\text { even } 1 \text { thoracic level treated w/ kyphoplasty. }\end{array}$ \\
\hline Lumbar & $\begin{array}{l}\text { This distinguishes patients who have had at least } 1 \text { lumbar level treated w/ a kyphoplasty \& those who have not had even } 1 \\
\text { lumbar level treated w/ kyphoplasty. }\end{array}$ \\
\hline$>1$ level & $\begin{array}{l}\text { This distinguishes btwn patients who have had more than } 1 \text { level treated in a single surgical case \& those who have had } \\
\text { only } 1 \text { level treated at any surgical setting. }\end{array}$ \\
\hline Multiple ops & $\begin{array}{l}\text { This distinguishes btwn patients who have had more than } 1 \text { surgical intervention \& those who have had only } 1 \text { surgical } \\
\text { intervention, regardless of number of levels treated. }\end{array}$ \\
\hline
\end{tabular}

care provider were significantly more likely to have been screened with a DEXA scan, to have had more than 1 fractured level, and to have been treated with vitamin D and calcium (Table 2). No significant difference was noted in the rate of treatment with bisphosphonates or parathormone.
Conversely, patients evaluated for preoperative clearance by their primary care provider were more likely to have been treated with bisphosphonates than those evaluated by an in-house hospitalist only (Table 2). However, no significant association could be established in other parameters of osteoporosis treatment and screening. 
TABLE 2. Associations ( $p$ values) between independent and dependent variables (2-tailed Fisher's test)

\begin{tabular}{|c|c|c|c|c|c|c|c|c|c|c|c|c|}
\hline $\begin{array}{l}\text { Independent } \\
\text { Variable }\end{array}$ & DEXA & $\begin{array}{l}\text { Vitamin } \\
\text { D }\end{array}$ & $\mathrm{Ca}^{++}$ & Calcitonin & Bisph & rPTH & $\begin{array}{c}\text { Vitamin D/ } \\
\text { Calcium/ } \\
\text { Calcitonin }\end{array}$ & Bisph/PTH & $\begin{array}{c}\text { Thoracic } \\
\text { Level }\end{array}$ & $\begin{array}{l}\text { Lumbar } \\
\text { Level }\end{array}$ & $>1$ Level & $\begin{array}{c}\text { Multiple } \\
\text { Ops }\end{array}$ \\
\hline Sex & 0.69 & 0.3 & 0.09 & 1.0 & 0.2 & 0.50 & 0.46 & 0.29 & 0.63 & 0.33 & 0.45 & 0.35 \\
\hline Initial encounter & 0.29 & 0.34 & 0.79 & 0.59 & 0.17 & 1.0 & 0.49 & 0.11 & 0.26 & $0.0001^{*}$ & 0.09 & 0.55 \\
\hline Mechanism & 0.19 & 0.31 & 0.69 & 1.0 & 0.15 & 0.51 & 0.42 & 0.096 & 0.42 & 0.84 & 0.06 & $0.03 \dagger$ \\
\hline Referral source & $0.018 \ddagger$ & $0.0032 \S$ & $0.01 \rrbracket$ & 0.36 & 0.56 & 1.0 & $0.0003^{* *}$ & 1.0 & 0.24 & 0.84 & $0.003+\dagger$ & 1.0 \\
\hline Steroids & 0.64 & 1.0 & 1.0 & 0.52 & 0.42 & 1.0 & 0.42 & 0.4 & 0.57 & 0.39 & 0.24 & 0.25 \\
\hline Smoking history & 1.0 & 0.58 & 0.75 & 0.17 & 0.69 & 1.0 & 0.18 & 0.46 & 0.59 & 0.29 & 0.16 & 0.29 \\
\hline Preop evaluation & 1.0 & 0.12 & 0.24 & 0.64 & $0.0046 \neq \ddagger$ & 1.0 & 0.28 & $0.0046 \S \S$ & 0.14 & 0.089 & 0.18 & 0.41 \\
\hline
\end{tabular}

Bisph = bisphosphonate; $\mathrm{PCP}=$ primary care physician; $\mathrm{PTH}=$ parathormone; $\mathrm{rPTH}=$ recombinant $\mathrm{PTH}$.

* Outpatient 56\%, hospital $36 \%$.

† Unprovoked $24 \%$, minor trauma $7 \%$.

$\ddagger$ Non-PCP $21 \%$, PCP $5 \%$.

$\S$ Non-PCP 56\%, PCP 26\%.

ๆ Non-PCP 41\%, PCP 17\%.

** Non-PCP 64\%, PCP 32\%.

†† Non-PCP 54\%, PCP 25\%.

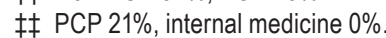

$\S \S$ PCP 21\%, internal medicine 0\%.

\section{Discussion}

Previous literature has reported bone density screening in $<3 \%$ to $38 \%$ of patients discharged from hospitals with known osteoporotic fractures; and appropriate medical therapy, such as bisphosphonates or parathormone, in $22 \%-38 \% .^{6,14,31,39}$ DEXA screening was performed in $10 \%$ of patients in our cohort; vitamin D, calcium, and bisphosphonate therapy were documented in 38\%, 26\%, and $13 \%$ of our cohort, respectively.

No statistical significance was noted in most treatment parameters, regardless of whether the patient was referred to the outpatient setting or evaluated in the emergency room first. Patients with unprovoked fractures were more likely to undergo multiple surgeries compared with those with minor trauma, perhaps indicating a more fragile state predisposing to further spontaneous fractures. Referral from a specialist rather than a primary care physician was associated with statistically significant improvement in compliance with bone density screening, as well as vitamin $\mathrm{D}$ and calcium therapy. One can theorize that this may be because the patient's chart had been reviewed by more than 1 physician and perhaps by subspecialists, thereby increasing episodes of physician-patient interaction and opportunities for implementing therapies. This same group, referred by specialists other than the primary

TABLE 3. Percentage of all patients with documented interventions

\begin{tabular}{lc}
\hline \multicolumn{1}{c}{ Intervention } & Percentage \\
\hline DEXA & 10 \\
\hline Vitamin D & 38 \\
\hline Calcium & 26 \\
\hline Calcitonin & 5 \\
\hline Bisphosphonates & 13 \\
\hline Recombinant parathormone & 2 \\
\hline
\end{tabular}

care provider, was more likely to have multiple fractures, raising the possibility that their disease process was more advanced or medically complex, thus encouraging primary care providers to seek specialist involvement. Nevertheless, even these medical measures were all suitable merely for fracture prevention. The standard of care for every patient in our cohort with vertebral compression fractures is treatment with bisphosphonate therapy or parathormone. All groups were poorly compliant with this therapy. Although patients who underwent preoperative evaluation by their primary care physician were significantly more likely to receive bisphosphonates compared with those only evaluated by a hospitalist, the former group was only $21 \%$ compliant. Shortcomings of our cohort evaluation include lack of pretest power analysis and the retrospective nature of our data. We have not analyzed dosing and drug regimen as part of our study; we maintain that this would be premature because of the overall poor compliance. We reported several variables, including patient referral source, initial setting of neurosurgical evaluation, and setting of preoperative evaluation (Table 1). Although aimed at representing the various stages of patient interaction, the exact implication of our categories is unclear and their external validity is questionable. Unique patient experiences are difficult to quantify, and detailed patient interviews may enable a qualitative evaluation of the sources of low compliance. In reporting the data for our cohort, we were

TABLE 4. Primary insurance provider

\begin{tabular}{lc}
\hline \multicolumn{1}{c}{ Provider } & No. of Patients $(\%)$ \\
\hline Medicare & $76(73.08)$ \\
\hline Private & $18(17.31)$ \\
\hline Medicaid & $5(4.81)$ \\
\hline Workers' compensation & $3(2.88)$ \\
\hline Veterans Affairs & $2(1.92)$ \\
\hline
\end{tabular}


TABLE 5. Correlation of age with other variables (univariate logistic regression)

\begin{tabular}{lccc}
\hline \multicolumn{1}{c}{ Variable } & p Value & OR & $95 \% \mathrm{Cl}$ \\
\hline DEXA & 0.2430 & 0.974 & $0.932-1.018$ \\
\hline Vitamin D & 0.0585 & 1.037 & $0.999-1.078$ \\
\hline Calcium & 0.2776 & 1.022 & $0.982-1.064$ \\
\hline Calcitonin & 0.4117 & 1.043 & $0.944-1.152$ \\
\hline Bisphosphonates & 0.5194 & 1.017 & $0.966-1.070$ \\
\hline Parathormone & 0.7527 & 0.984 & $0.891-1.087$ \\
\hline Vitamin D/calcium/calcitonin & 0.5303 & 1.010 & $0.978-1.044$ \\
\hline Bisphosphonates/parathormone & 1.0000 & 1.000 & $0.957-1.045$ \\
\hline Thoracic & 0.6106 & 0.992 & $0.960-1.024$ \\
\hline Lumbar & 0.2538 & 1.019 & $0.986-1.053$ \\
\hline$>1$ level & 0.7244 & 0.994 & $0.962-1.027$ \\
\hline Multiple ops & 0.0781 & 1.054 & $0.994-1.116$ \\
\hline
\end{tabular}

attempting to identify various possible physician referral and evaluation sequences and schemas. Unfortunately, no single scheme was overwhelmingly successful in implementing the appropriate osteoporosis therapies.

Compliance was generally poor despite evaluation by multiple teams including, in various combinations, an outpatient primary provider, an outpatient medical specialist, an inpatient medical hospitalist team, and the neurosurgery team. Although tempting, it would be inappropriate to lay blame with any single team. The inpatient hospitalist may not see management of a chronic disease like osteoporosis to be the purpose of his or her consultation and may limit comments to perioperative cardiovascular risk assessment. The primary care physician may not be kept abreast of an acute diagnosis of fracture and is not the primary provider at the point of care, especially if the patient presents to the hospital emergency room. The neurosurgeon, although clearly at the forefront of the point-ofcare patient interaction, may not see medical management of osteoporosis as a part of his or her scope of expertise or purview of care.

Three categories of solutions may be proposed: systems-based solutions, personnel-based solutions, and comprehensive interdisciplinary physician behavior modification interventions. A systems-based solution would, most likely, rely on outpatient and/or inpatient health record technology to create an automatically generated reminder or recommendation when patients who have undergone kyphoplasty visit the department. This can be performed via extant mechanisms in most updated outpatient and inpatient electronic health record systems. Depending on the scope and particular arrangement of the practice or hospital, the nature of the reminder could be a recommendation to start a medication, an automated letter to the patient's primary care provider reminding them of the current guidelines, or a streamlined referral to an endocrinologist.

A personnel-based solution would consist of a dedicated osteoporosis specialist-whether a physician, a midlevel provider, or a clinical pharmacist-who would be entrusted with ensuring medical care of patients with osteoporotic fractures. After being automatically notified of all patients undergoing vertebral augmentation, the dedicated osteoporosis specialist's role could include direct patient counseling, treatment regimen design and prescription, and/or recommending treatment protocols to the primary surgeon.

Systematic interventions with quantifiable outcomes to affect physician behavior modification have been reported in many fields, often with success. ${ }^{4,32}$ These performance improvement interventions, which often demand interdisciplinary cooperation, may include educational materials, training workshops, lectures, audit/feedback mechanisms, and physician opinion leaders, among others. Such projects are time intensive, costly, and may be sustainable for the timeframe of the measured outcomes with diminishing compliance thereafter. Yet, they provide a systematic intervention paradigm and quantifiable outcome measures that can be shared with the academic and scientific community. Despite these advantages, the reproducibility and external validity of such data are suspect because such interventions are usually tailored to particular practice patterns, personalities, and academic environments.

\section{Conclusions}

We report poor compliance with recommended medical therapies among patients with osteoporotic compression fractures undergoing kyphoplasty. Further studies are required to analyze barriers to care. Systems-based, personnel-based, and physician behavior modification intervention options may improve compliance with screening and treatment guidelines in patients with vertebral compression fractures referred to the neurosurgery service for percutaneous cement augmentation procedures.

\section{Acknowledgments}

We thank Debra J. Zimmer for editorial assistance.

\section{References}

1. Barrett-Connor E: The economic and human costs of osteoporotic fracture. Am J Med 98 (2A):3S-8S, 1995

2. Black DM, Cummings SR, Karpf DB, Cauley JA, Thompson DE, Nevitt MC, et al: Randomised trial of effect of alendronate on risk of fracture in women with existing vertebral fractures. Lancet 348:1535-1541, 1996

3. Blake GM, Fogelman I: Role of dual-energy X-ray absorptiometry in the diagnosis and treatment of osteoporosis. J Clin Densitom 10:102-110, 2007

4. Brennan N, Mattick K: A systematic review of educational interventions to change behaviour of prescribers in hospital settings, with a particular emphasis on new prescribers. Br J Clin Pharmacol 75:359-372, 2013

5. Burger H, van Daele PL, Algra D, Hofman A, Grobbee DE, Schütte HE, et al: Vertebral deformities as predictors of nonvertebral fractures. BMJ 309:991-992, 1994

6. Castel H, Bonneh DY, Sherf M, Liel Y: Awareness of osteoporosis and compliance with management guidelines in patients with newly diagnosed low-impact fractures. Osteoporos Int 12:559-564, 2001

7. Chrischilles E, Shireman T, Wallace R: Costs and health effects of osteoporotic fractures. Bone 15:377-386, 1994

8. Cummings SR, Black DM, Thompson DE, Applegate WB, Barrett-Connor E, Musliner TA, et al: Effect of alendronate on risk of fracture in women with low bone density but without vertebral fractures: results from the Fracture Intervention Trial. JAMA 280:2077-2082, 1998 
9. Cummings SR, Nevitt MC, Browner WS, Stone K, Fox KM, Ensrud KE, et al: Risk factors for hip fracture in white women. N Engl J Med 332:767-773, 1995

10. Delmas PD, van de Langerijt L, Watts NB, Eastell R, Genant $\mathrm{H}$, Grauer A, et al: Underdiagnosis of vertebral fractures is a worldwide problem: the IMPACT study. J Bone Miner Res 20:557-563, 2005

11. Donovan MA, Khandji AG, Siris E: Multiple adjacent vertebral fractures after kyphoplasty in a patient with steroidinduced osteoporosis. J Bone Miner Res 19:712-713, 2004

12. Ensrud KE, Schousboe JT: Clinical practice. Vertebral fractures. N Engl J Med 364:1634-1642, 2011

13. Ettinger B, Black DM, Mitlak BH, Knickerbocker RK, Nickelsen T, Genant HK, et al: Reduction of vertebral fracture risk in postmenopausal women with osteoporosis treated with raloxifene: results from a 3-year randomized clinical trial. JAMA 282:637-645, 1999

14. Freedman KB, Kaplan FS, Bilker WB, Strom BL, Lowe RA: Treatment of osteoporosis: are physicians missing an opportunity? J Bone Joint Surg Am 82-A:1063-1070, 2000

15. Grafe IA, Da Fonseca K, Hillmeier J, Meeder PJ, Libicher M, Nöldge G, et al: Reduction of pain and fracture incidence after kyphoplasty: 1-year outcomes of a prospective controlled trial of patients with primary osteoporosis. Osteoporos Int 16:2005-2012, 2005

16. Grohs JG, Matzner M, Trieb K, Krepler P: Minimal invasive stabilization of osteoporotic vertebral fractures: a prospective nonrandomized comparison of vertebroplasty and balloon kyphoplasty. J Spinal Disord Tech 18:238-242, 2005

17. Hoerger TJ, Downs KE, Lakshmanan MC, Lindrooth RC, Plouffe L Jr, Wendling B, et al: Healthcare use among U.S. women aged 45 and older: total costs and costs for selected postmenopausal health risks. J Womens Health Gend Based Med 8:1077-1089, 1999

18. Johnell O, Kanis JA, Odén A, Sernbo I, Redlund-Johnell I, Petterson C, et al: Mortality after osteoporotic fractures. Osteoporos Int 15:38-42, 2004

19. Kado DM, Browner WS, Palermo L, Nevitt MC, Genant HK, Cummings SR: Vertebral fractures and mortality in older women: a prospective study. Arch Intern Med 159:12151220, 1999

20. Kanis JA, Burlet N, Cooper C, Delmas PD, Reginster JY, Borgstrom F, et al: European guidance for the diagnosis and management of osteoporosis in postmenopausal women. Osteoporos Int 19:399-428, 2008

21. Kanis JA, McCloskey EV: Epidemiology of vertebral osteoporosis. Bone 13 (Suppl 2):S1-S10, 1992

22. Kleerekoper M, Nelson DA: Which bone density measurement? J Bone Miner Res 12:712-714, 1997

23. Ledlie JT, Renfro MB: Kyphoplasty treatment of vertebral fractures: 2-year outcomes show sustained benefits. Spine (Phila Pa 1976) 31:57-64, 2006

24. Liberman UA, Weiss SR, Bröll J, Minne HW, Quan H, Bell $\mathrm{NH}$, et al: Effect of oral alendronate on bone mineral density and the incidence of fractures in postmenopausal osteoporosis. N Engl J Med 333:1437-1443, 1995

25. Lieberman IH, Dudeney S, Reinhardt MK, Bell G: Initial outcome and efficacy of "kyphoplasty" in the treatment of painful osteoporotic vertebral compression fractures. Spine (Phila Pa 1976) 26:1631-1638, 2001

26. Lippuner K, von Overbeck J, Perrelet R, Bosshard H, Jaeger $P$ : Incidence and direct medical costs of hospitalizations due to osteoporotic fractures in Switzerland. Osteoporos Int 7:414-425, 1997

27. Lyles KW: Management of patients with vertebral compression fractures. Pharmacotherapy 19:21S-24S, 1999

28. Machinis TG, Fountas KN, Feltes CH, Johnston KW, Robinson JS: Pain outcome and vertebral body height restoration in patients undergoing kyphoplasty. South Med J 99:457-460, 2006

29. Melton LJ III, Thamer M, Ray NF, Chan JK, Chesnut CH III, Einhorn TA, et al: Fractures attributable to osteoporosis: report from the National Osteoporosis Foundation. J Bone Miner Res 12:16-23, 1997

30. National Osteoporosis Foundation: Osteoporosis: review of the evidence for prevention, diagnosis and treatment and cost-effectiveness analysis. Introduction. Osteoporos Int 8 (Suppl 4):S7-S80, 1998

31. Neuner JM, Zimmer JK, Hamel MB: Diagnosis and treatment of osteoporosis in patients with vertebral compression fractures. J Am Geriatr Soc 51:483-491, 2003

32. Oxman AD, Thomson MA, Davis DA, Haynes RB: No magic bullets: a systematic review of 102 trials of interventions to improve professional practice. CMAJ 153:1423-1431, 1995

33. Phillips FM: Minimally invasive treatments of osteoporotic vertebral compression fractures. Spine (Phila Pa 1976) 28 (15 Suppl):S45-S53, 2003

34. Pluijm SM, Tromp AM, Smit JH, Deeg DJ, Lips P: Consequences of vertebral deformities in older men and women. $\mathbf{J}$ Bone Miner Res 15:1564-1572, 2000

35. Pradhan BB, Bae HW, Kropf MA, Patel VV, Delamarter RB: Kyphoplasty reduction of osteoporotic vertebral compression fractures: correction of local kyphosis versus overall sagittal alignment. Spine (Phila Pa 1976) 31:435-441, 2006

36. Ray NF, Chan JK, Thamer M, Melton LJ III: Medical expenditures for the treatment of osteoporotic fractures in the United States in 1995: report from the National Osteoporosis Foundation. J Bone Miner Res 12:24-35, 1997

37. Riggs BL, Melton LJ III: The worldwide problem of osteoporosis: insights afforded by epidemiology. Bone 17 (5 Suppl):505S-511S, 1995

38. Ross PD, Davis JW, Epstein RS, Wasnich RD: Pre-existing fractures and bone mass predict vertebral fracture incidence in women. Ann Intern Med 114:919-923, 1991

39. Simonelli C, Chen YT, Morancey J, Lewis AF, Abbott TA: Evaluation and management of osteoporosis following hospitalization for low-impact fracture. J Gen Intern Med 18:17-22, 2003

40. Tatsumi RL, Ching AC, Byrd GD, Hiratzka JR, Threlkeld JE, Hart RA: Predictors and prevalence of patients undergoing additional kyphoplasty procedures after an initial kyphoplasty procedure. Spine J 10:979-986, 2010

41. Uppin AA, Hirsch JA, Centenera LV, Pfiefer BA, Pazianos AG, Choi IS: Occurrence of new vertebral body fracture after percutaneous vertebroplasty in patients with osteoporosis. Radiology 226:119-124, 2003

42. Voggenreiter G: Balloon kyphoplasty is effective in deformity correction of osteoporotic vertebral compression fractures. Spine (Phila Pa 1976) 30:2806-2812, 2005

\section{Disclosures}

The authors report no conflict of interest concerning the materials or methods used in this study or the findings specified in this paper.

\section{Author Contributions}

Conception and design: all authors. Acquisition of data: all authors. Analysis and interpretation of data: Pollina, Morr, Shakir. Drafting the article: Morr, Dimopoulos. Critically revising the article: all authors. Reviewed submitted version of manuscript: all authors.

\section{Correspondence}

John Pollina, University at Buffalo Neurosurgery, 100 High St., Ste. B4, Buffalo, NY 14203. email: editorialoffice@ubns.com. 